\title{
Hybrid aortic arch repair for dissecting aneurysm
}

\author{
Elsa Madeleine Faure, MD, Ludovic Canaud, MD, PhD, Charles Marty-Ané, MD, PhD, and \\ Pierre Alric, MD, PhD
}

\section{ABSTRACT}

Objective: This study analyzed the outcome of a combined endovascular and debranching procedure for hybrid aortic arch repair in patients with chronic dissecting aortic aneurysms involving the aortic arch.

Methods: We reviewed all consecutive patients who underwent hybrid aortic arch repair for dissecting aneurysm at the Arnaud de Villeneuve Hospital.

Results: A total of 33 consecutive patients between March 2005 and September 2015 were included. Patients' mean age was $65.1 \pm 12.2$ years. Mean aneurysm diameter was $60.3 \pm 14.2 \mathrm{~mm}$. Patients were treated for aneurysm diameter $55 \mathrm{~mm}$ or greater $(\mathrm{n}=28)$, aortic growth more than $1 \mathrm{~cm} /$ year $(\mathrm{n}=3)$, or rupture $(\mathrm{n}=2)$. Eleven complete supra-aortic debranchings were performed in zone 0 , with 2 concomitant replacements of the ascending aorta. Partial aortic arch debranching was performed in 22 patients (zone $1=8$; zone $2=14$ ). Technical success was achieved in $97 \%$ of patients. There was no in-hospital death. One patient died of decompensated cirrhosis on day 20 , resulting in a 30-day mortality of $3 \%$. One patient had major cerebrovascular complications (3\%). Spinal cord ischemia was observed in 1 patient $(3 \%)$, with complete recovery after spinal fluid drainage. Retrograde dissection occurred in 1 patient $(3 \%)$. After a mean follow-up of 24.3 months (range, 0.6-104.8 months), the overall mortality was $12 \%(\mathrm{n}=4)$ with 3 additional deaths. Endoleak was reported in 6 patients $(18 \%)$, of whom 2 required reintervention. Overall, 8 reinterventions were performed $(24 \%)$, with a mean time from intervention of 8.7 months (range, 1.2-24.6 months).

Conclusions: Hybrid aortic arch repair for dissecting aneurysm is associated with acceptable early and midterm major morbidity and mortality, even for patients treated in zone 0 . However, given the high rate of reintervention and endoleak,

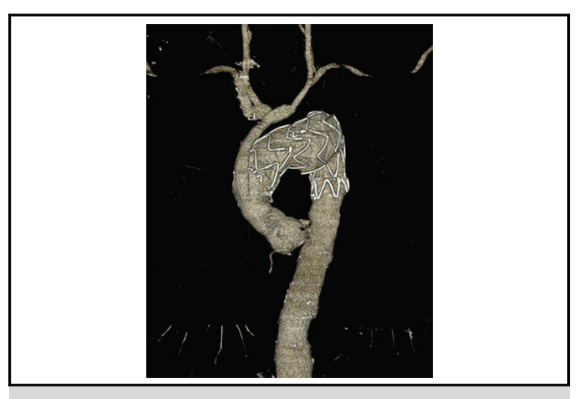

Zone 0 debranching and endovascular repair for dissecting aneurysm of the aortic arch.

\section{Central Message}

HAR is a safe alternative for dissecting aneurysm of the aortic arch even for patients treated in zone 0 .

\section{Perspective}

Few reports are available concerning HAR for dissecting aneurysm, and the best therapies for this pathology remain debated. This study is the largest series to date on HAR for dissecting aneurysm. We report an acceptable morbidity-mortality rate, even in zone 0 , and we assume that HAR is a safe alternative for dissecting aneurysm of the aortic arch.

See Editorial Commentary page 169. close follow-up is required. (J Thorac Cardiovasc Surg 2016;152:162-8)

In case of aneurysmal degeneration of aortic dissection, $25 \%$ of patients with type B aortic dissection have aortic arch involvement. ${ }^{1}$ However, the best therapies for dissecting aneurysm involving the aortic arch remain debated. ${ }^{2,3}$ Conventional surgical open repair offers durable results but requires arch replacement during deep hypothermic circulatory arrest. Despite advances in surgical techniques and postoperative management, this open procedure is

From the Department of Vascular and Thoracic Surgery, Arnaud de Villeneuve Hospital, Montpellier, France.

Received for publication Dec 1, 2015; revisions received Feb 12, 2016; accepted for publication March 1, 2016; available ahead of print April 8, 2016.

Address for reprints: Elsa Madeleine Faure, MD, Service de Chirurgie Vasculaire et Thoracique, Hôpital Arnaud de Villeneuve, 191 av Doyen Gaston Giraud, 34090 Montpellier, France (E-mail: elsafaure@ hotmail.com).

$0022-5223 / \$ 36.00$

Copyright (c) 2016 by The American Association for Thoracic Surgery

http://dx.doi.org/10.1016/j.jtcvs.2016.03.020 still associated with a significant in-hospital mortality rate. ${ }^{4}$ Thoracic endovascular aortic repair (TEVAR) offers a less-invasive surgical procedure but requires hybrid surgery that includes the use of open surgical procedures, such as debranching for revascularization of cervical branches to provide an adequate landing zone in different segments of the aortic arch. Hybrid aortic arch repair (HAR) has been reported mainly for degenerative aneurysms, traumatic aortic injuries, or penetrating ulcers of the aortic arch. Few reports currently are available in the literature regarding HAR for chronic dissecting aneurysms,

Scanning this QR code will take you to the article title page. 


\section{Abbreviations and Acronyms \\ $\mathrm{CT}=$ computed tomography \\ HAR = hybrid aortic arch repair \\ LCCA $=$ left common carotid artery \\ LSA $=$ left subclavian artery \\ TEVAR $=$ thoracic endovascular aortic repair}

although HAR in this particular context is faced with several problems: a higher risk of both early complications, such as retrograde dissection, ${ }^{5}$ and late complications, such as endoleak and reintervention, ${ }^{6}$ compare with HAR for other aortic arch disease. If some promising early results have been recently reported, ${ }^{7}$ larger series and long-term reports are lacking.

The purpose of this study was to evaluate the midterm outcome of HAR for patients with chronic dissecting aneurysms involving the aortic arch in the largest series reported.

\section{MATERIALS AND METHODS}

The study was approved by the institutional review board.

\section{Patients}

We performed a retrospective review of our single-center results of all patients who underwent HAR for a dissecting aneurysm. Patients were included from 2005 (first HAR for dissecting aneurysm in our institution) to March 2015. Inclusion criteria for HAR included dissecting aneurysm with maximal diameter $55 \mathrm{~mm}$ or greater, aortic growth $1 \mathrm{~cm} /$ year or more, or rupture, and involvement of the aortic arch or an inadequate landing zone for TEVAR at the proximal descending aorta $(<20 \mathrm{~mm})$.

\section{Demographic and Procedural Data}

Collected variables were categorized as demographic and preoperative (ie, age, sex, comorbidities, previous aortic surgery, dissecting aneurysm anatomy, and aortic dissection complications such as rupture), intraoperative (ie, debranching procedure, TEVAR procedure, and completion angiogram), and postoperative outcomes (stroke, spinal cord ischemia, reintervention, endoleak, aneurysm diameter, false lumen status, primary patency, and mortality). We used the Ishimaru classification to categorize the proximal landing zone of the stent-graft. Study follow-up time was defined as the date of the last postoperative clinical evaluation. All surviving patients underwent at least postoperative surveillance imaging at 1 month, 6 months, and then annually. All available preoperative and postoperative imaging results were reviewed, which included thoracic CT angiography performed within the Arnaud de Villeneuve University Hospital system and those performed at outside facilities, when available.

\section{Debranching Procedure}

All procedures were performed under general anesthesia in an operating room and with the use of intravenous systemic heparin.

- Debranching and revascularization in zone 0 were performed through a median sternotomy. Bifurcated Dacron grafts $(14 \times 7 \mathrm{~mm}$ or $16 \times 8 \mathrm{~mm}$ ) were inserted from the ascending aorta with partial crossclamping to the brachiocephalic trunk, left common carotid artery (LCCA), and left subclavian artery (LSA). For the past 2 years, partial crossclamping of the ascending aorta has been performed under rapid pacing to avoid retrograde dissection.

- Debranching and revascularization in zone 1 were mainly performed through cervico-manubriotomy with sequential transposition of the LCCA and the LSA as we previously described. ${ }^{8}$ For patients deemed unsuitable for sequential transposition because of proximal atherosclerotic lesions of the supra-aortic trunks, extra-anatomic revascularization of LCCA and LSA was performed with a carotid-carotid bypass, followed by a left carotid-subclavian transposition.

- Debranching and revascularization in zone 2: Revascularization of the LSA was performed each time it was possible without regard to vertebral circulation.

- In case of aortic origin of left vertebral artery viewed on preoperative CT scan, revascularization of this artery was performed by transposition into the LSA.

- To avoid intraoperative complications, in particular retrograde aortic dissection, we used graft replacement of the ascendant aorta when the aortic diameter was greater than $40 \mathrm{~mm}$.

\section{Thoracic Endovascular Aortic Repair Procedure}

All TEVAR procedures were performed in an operating room with patients under general anesthesia. In most cases, TEVAR was accomplished as a sequential concomitant procedure with supra-aortic debranching. In 2 zone 0 landing cases, because of a perioperative unstable blood pressure status, a staged procedure was chosen and TEVAR was performed in the following days (4-7 days). Spinal fluid drainage was performed postoperatively in case of spinal cord ischemia symptoms.

Through a transfemoral approach, a 0.035 Terumo (Tokyo, Japan) guidewire was used to catheterize the true lumen to the ascending aorta under fluoroscopy. Through a $5 \mathrm{~F}$ pigtail catheter, the guidewire was exchanged for a thoracic stiff-wire (Lunderquist, Cook, France). Transesophageal echography was performed to control the placement of the wire into the true lumen. A 5F pigtail catheter was placed into the aortic arch through the transposed vessels for angiographies during the procedure For the past 2 years, we have systematically used rapid pacing during stent-graft deployment to reduce blood pressure in the aortic arch and improve the stent-graft placement accuracy. Over the period of study inclusion, 5 different stent grafts were used: Excluder stent graft (WL Gore \& Associates Inc, Flagstaff, Ariz); TAG stent graft (WL Gore \& Associates Inc); Talent (Medtronic Inc, Sunrise, Fla); Valiant devices (Medtronic Inc), and Zenith TX2 stent graft (Cook, Bloomington, Ind). Stent graft selection was at the discretion of the surgeon. Stent-graft sizing was determined by measuring on the computed tomography (CT) angiogram the proximal and distal landing zone diameters in an orthogonal view using center-line reconstruction. The decision to perform HAR to extend the proximal landing zone was based on the location of the proximal entry tear, and the distal extension of the stent-graft was based on the distal extension of the aneurysm. In case of type 2 thoracoabdominal aorta dissecting aneurysm, a second-stage procedure for open repair of the abdominal aorta was planned. Stent-graft diameter was selected with an oversizing of approximately $10 \%$ compared with the proximal diameter of the native nondissected aorta to prevent a new intimal tear and retrograde dissection. ${ }^{5}$ If the patient was previously treated for a type A dissection, the proximal anchoring zone was in the prior aortic graft. For other patients, the sizing of the stent-graft diameter was performed on preoperative CT angiogram with an oversizing of approximately $10 \%$. Technical success was defined as exclusion of the dissecting aneurysm without endoleak at the final perioperative angiogram and on transesophageal echography.

\section{Statistical Analysis}

Data are reported as mean standard deviation. Discrete data are given as counts and percentages. 
TABLE 1. Baseline characteristics of 33 patients with hybrid aortic arch repair for dissecting aneurysm

\begin{tabular}{lc}
\hline \multicolumn{1}{c}{ Variable } & No. $(\%)$ \\
\hline Male sex & $26(79)$ \\
American Society of Anesthesiologist $3+4$ & $23(70)$ \\
Hypertension & $25(76)$ \\
Smoke & $13(39)$ \\
Chronic obstructive pulmonary disease & $4(12)$ \\
Obesity & $4(12)$ \\
Atrial fibrillation & $4(12)$ \\
Coronary artery disease & $4(12)$ \\
Renal insufficiency & $2(6)$ \\
Marfan syndrome & $3(9)$ \\
Previous aortic repair & $14(42)$ \\
Surgery for type A dissection & $9(27)$ \\
TEVAR for type B dissection & $4(12)$ \\
Surgery for abdominal aortic aneurysm & $1(3)$ \\
\hline
\end{tabular}

TEVAR, Thoracic endovascular aortic repair.

\section{RESULTS}

\section{Patients and Dissecting Aneurysm Characteristics}

From 2005 to 2015, 423 TEVAR procedures were performed in 330 patients in our department. Among them, 33 patients were treated by HAR for chronic aortic dissecting aneurysm. During this period, all patients treated in our department for a chronic dissecting aneurysm involving the aortic arch were treated by HAR. Preoperative patient characteristics are reported in Table 1. Patients' mean age at the time of the procedure was $65.1 \pm 12.2$ years. Mean aneurysm diameter was $60.3 \pm 14 \mathrm{~mm}$. Maximal aortic diameters were located in the arch in 6 patients $(18 \%)$, the proximal descending aorta in 24 patients $(73 \%)$, and the distal part of the descending thoracic aorta in 3 patients $(9 \%)$. Patients were treated for aneurysm diameter $55 \mathrm{~mm}$ or greater $(\mathrm{n}=28)$, aortic growth more than $1 \mathrm{~cm} /$ year $(\mathrm{n}=3)$, or rupture $(n=2)$. Four patients had a type 2 thoracoabdominal aorta dissecting aneurysm, and a second-stage procedure for open repair of the abdominal aorta was planned.

\section{Debranching Procedures}

Details of the 33 supra-aortic debranching procedures are described in Table 2. Complete supra-aortic debranching (Figure 1) was performed in 11 patients $(33 \%)$ in zone 0 , comprising 2 concomitant replacements of the ascending aorta for diameter greater than $40 \mathrm{~mm}(\mathrm{n}=1)$ and nontreated chronic type A dissection $(\mathrm{n}=1)$. Partial aortic arch debranching was performed in 22 patients $(67 \%)$, including zone 1 in $8(24 \%)$ and zone 2 in $14(42 \%)$. Revascularization of the LSA was performed in 32 patients. In 4 patients with aortic origin of left vertebral artery, revascularization of this artery was performed by transposition into the LSA.

\section{Thoracic Endovascular Aortic Repair Procedure}

In all but 2 patients (94\%), TEVAR was accomplished as a sequential concomitant procedure with supra-aortic
TABLE 2. Details of the 33 supra-aortic debranching procedures

\begin{tabular}{lc}
\hline \multicolumn{1}{c}{ Variable } & No. $(\%)(\mathbf{N}=\mathbf{3 3})$ \\
\hline Zone 0 debranching & $11(33)$ \\
Ascending Ao/graft-IA-LCCA-LSA bypass & $9(27)$ \\
Without LSA revascularization & $1(3)$ \\
Ascending Ao-IA-LCCA bypass and & $1(3)$ \\
LSA + VA transposition (2 stage procedure) & \\
Zone 1 debranching & $8(24)$ \\
LCCA + LSA transposition & $6(18)$ \\
LCCA + LSA + VA transposition & $1(3)$ \\
RCCA-LCCA bypass + LSA transposition & $1(3)$ \\
Zone 2 debranching & $14(42)$ \\
LSA transposition & $12(36)$ \\
LSA + VA transposition & $2(6)$ \\
\hline
\end{tabular}

$A o$, Aorta; $I A$, innominate artery; $L C C A$, left common carotid artery; $L S A$, left subclavian artery; $V A$, vertebral artery; $R C C A$, right common carotid artery.

debranching. In $2(6 \%)$ zone 0 landing cases, a staged procedure was chosen because of perioperative unstable blood pressure status, and TEVAR was performed in the following days (4-7 days). One of these 2 patients had graft replacement of the ascending aorta and coronary bypass concomitant with supra-aortic vessels debranching. Mean stent-graft diameter was $37 \mathrm{~mm}$ (range, 31-46 mm), and mean length of aortic coverage was $200 \mathrm{~mm}$ (range, 100-300 mm).

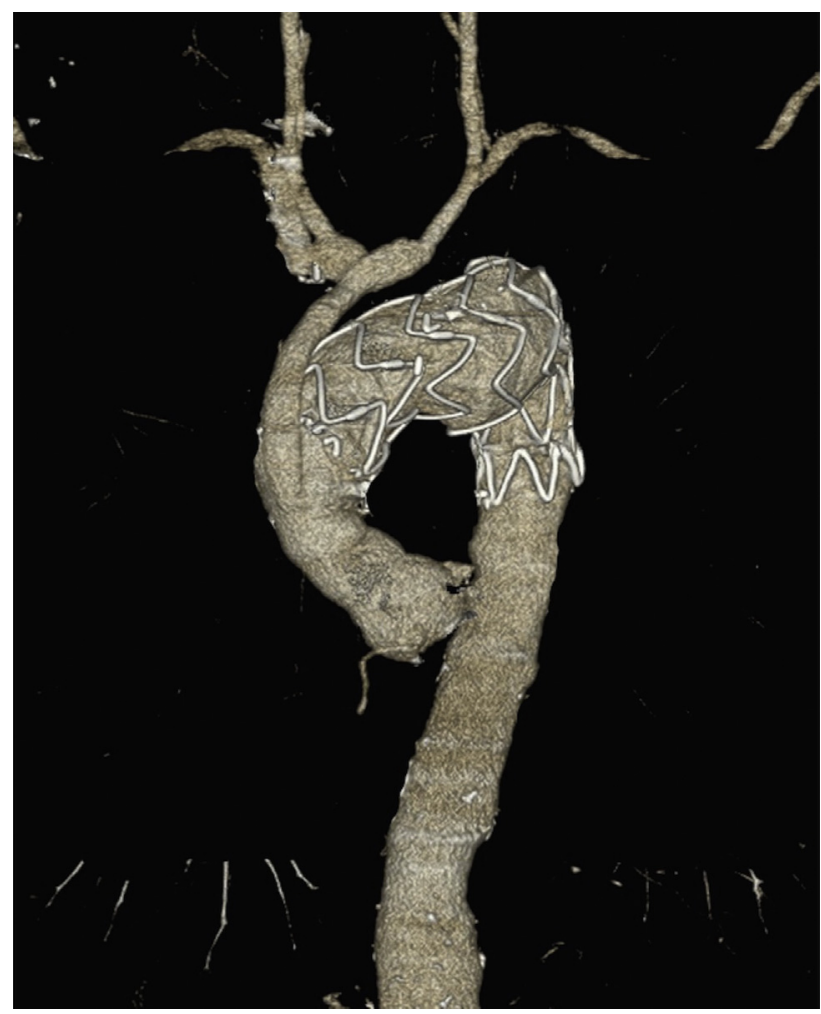

FIGURE 1. Zone 0 debranching and endovascular repair for dissecting aneurysm of the aortic arch. 
TABLE 3. Major morbidity and mortality according to the proximal landing zone

\begin{tabular}{llll}
\hline \multicolumn{1}{c}{ Zariables } & $\begin{array}{c}\text { Zone 0 }(\%) \\
\mathbf{N}=\mathbf{1 1}\end{array}$ & $\begin{array}{c}\text { Zone 1 }(\%) \\
\mathbf{N}=\mathbf{8}\end{array}$ & $\begin{array}{c}\text { Zone 2 }(\%) \\
\mathbf{N}=\mathbf{2 4}\end{array}$ \\
\hline Major morbidity & & & \\
Cerebrovascular complication & $2(18)$ & $0(0)$ & $0(0)$ \\
Spinal cord ischemia & $1(9)$ & $0(0)$ & $0(0)$ \\
Retrograde dissection & $0(0)$ & $1(12.5)$ & $0(0)$ \\
Mortality & $1(9)$ & $1(12.5)$ & $2(14)$ \\
\hline
\end{tabular}

Technical success was achieved in $97 \%$ of patients (32/33). The only failure constituted a stent-graft insertion through an antegrade approach to overcome inappropriate transfemoral stent-graft placement due to significant aortic curvatures. This patient had a complete supra-aortic debranching in zone 0 through a median sternotomy, which was used to perform the antegrade approach.

\section{Early ( $<30$ Days) Outcomes}

The mean length of hospital stay was 8 days (range, 4-61). Major morbidity and mortality rates according to the proximal landing zone are reported in Table 3.

Mortality. There was no in-hospital death. One patient died of a decompensated cirrhosis on day 20 , resulting in a 30-day mortality of 3\%.

Morbidity. Major morbidity was $12 \%(\mathrm{n}=4) ; 2$ patients had cerebrovascular complications $(6 \%), 1$ patient had a perioperative stroke, and 1 patient had a transient ischemic attack. Spinal cord ischemia was observed in 1 patient (3\%), with complete recovery after spinal fluid drainage. Retrograde dissection occurred in 1 patient $(3 \%) 4$ days after partial debranching and revascularization in zone 1 . $\mathrm{He}$ underwent a Bentall procedure with uncomplicated postoperative course.

Minor morbidity was 33\% $(\mathrm{n}=10)$ : Cardiac complications occurred in 1 patient $(3 \%)$, pulmonary complications occurred in 2 patients $(6 \%)$, and renal insufficiency requiring temporary dialysis developed in 2 patients $(6 \%)$. Five patients $(15 \%)$ had operative site complications (1 seroma, 4 hematomas) requiring surgical exploration.

\section{Late ( $>30$ Days) Outcomes}

Mortality. After a mean follow-up of 2 years (range, 20 days to 8.7 years), the overall mortality in our series was $12 \%(\mathrm{n}=4)$ with 3 late additional deaths: 1 patient at month 45 as a result of a type A dissection and 1 patient at month 2 after HAR. This patient was treated for a thoracoabdominal dissecting aneurysm and an ascending aorta diameter greater than $40 \mathrm{~mm}$. A 2-stage procedure was planned: stage 1 for replacement of the ascending aorta with zone 0 debranching and stent-graft placement in the thoracic aorta and stage 2 for open surgical repair of the abdominal aorta. The patient had an uneventful stage 1

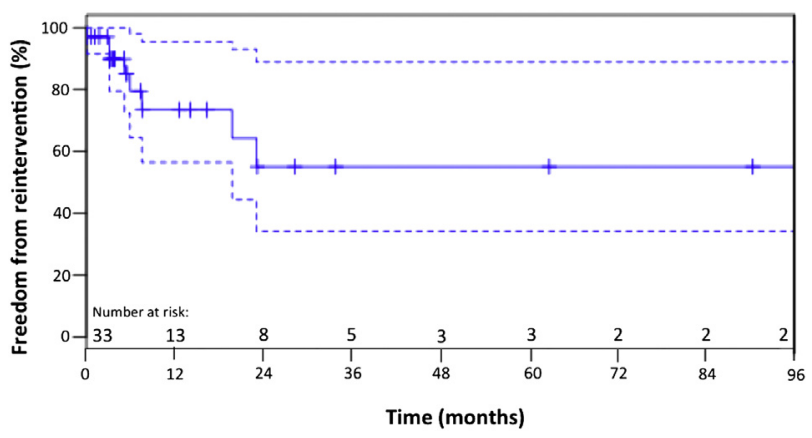

FIGURE 2. Freedom from reintervention is shown in 33 patients treated with supra-aortic debranching and TEVAR.

procedure but died 1 day after the second procedure. The last death was in a patient who was initially treated with zone 1 debranching and $200 \mathrm{~mm}$ stent-graft aortic length coverage, and developed a mediastinitis due to an ischemic esophageal necrosis. He was treated by esophagectomy and reconstruction by esophagogastric anastomosis 98 days post-HAR and died of respiratory failure in the intensive care unit 22 days after reintervention.

Morbidity. No bypass dysfunction was seen. Type Ia endoleak was reported in 2 patients $(6 \%)$. The first patient had a complete debranching and zone 0 stent-graft deployment; the 6-month follow-up CT scan showed a stent-graft migration with proximal type I endoleak. The second patient had a partial arch debranching and zone 2 stent-graft deployment. The endoleak was shown on the CT scan follow-up at 2 years and was considered as a late endoleak due to proximal aneurysmal evolution of the aorta. In addition, type $\mathrm{Ib}$ was reported in 4 patients (12\%), and type II was reported in 2 patients $(6 \%)$.

Overall, 8 major reinterventions were performed (24\%), with a mean time from intervention of 8.7 months (range, 1.2-24.6 months). Kaplan-Meier survival curves without reintervention are shown in Figure 2. Details of the 8 secondary major reinterventions are described in Table 4. There was 1 reintervention-related death $(12.5 \%)$. One patient died 2 years after secondary intervention for a type A dissection.

Aortic remodeling. After a mean follow-up of 2 years, complete aneurysm false lumen thrombosis at the level of the stent-graft occurred in 25 patients $(76 \%)$. On the last follow-up CT scan, the mean maximal aortic diameter in the treated thoracic aorta was $51.5 \mathrm{~mm}$ (range, 27-70 $\mathrm{mm}$ ), and the mean decrease of the maximal aortic diameter compared with preoperative CT scan was $8.1 \mathrm{~mm}$ (range, $-38 \mathrm{~mm}$ to $+13 \mathrm{~mm}$ ). Regression and stability of the maximal aneurysm diameter were observed in 26 patients $(79 \%)$ and 4 patients $(12 \%)$, respectively. One patient developed a dissecting thoracoabdominal aneurysm $60 \mathrm{~mm}$ distal to the stent-graft still not treated. 
TABLE 4. Details of the 8 major secondary procedures

\begin{tabular}{lcclll}
\hline Zone & Delay, day & Age, years & \multicolumn{1}{c}{ Reason } & Type of secondary procedure & Outcome \\
\hline 0 & 165 & 65 & TIbE & TEVAR: SG distal & Uneventful \\
0 & 189 & 79 & TIaE (SG migration) & TEVAR: SG proximal & Uneventful \\
1 & 4 & 62 & Retrograde type A dissection & Bentall procedure & Uneventful \\
1 & 98 & 81 & Ischemic esophageal necrosis & Esophagectomy & Death day 22 \\
1 & 240 & 67 & Aneurysm of the TAA & Open repair & Uneventful \\
1 & 630 & 67 & Lower limb malperfusion & TEVAR: SG distal & Uneventful \\
2 & 98 & 51 & Aneurysm of the DTA & TEVAR: SG distal & Uneventful \\
2 & 737 & 66 & TIaE & TEVAR: SG proximal & Death from TAD month 20 \\
\hline
\end{tabular}

TIbE, Type Ib endoleak; TEVAR, thoracic endovascular aortic repair; SG, stent-graft; TIaE, type Ia endoleak; TAA, thoracoabdominal aorta; DTA, descending thoracic aorta; $T A D$, type A dissection.

\section{DISCUSSION}

HAR has emerged in recent years as an effective alternative to conventional surgical repair in various diseases of the aortic arch by improving morbidity and mortality, especially among high-risk surgical patients. ${ }^{9-11}$ However, few data are currently available concerning HAR in the specific area of dissection and in dissecting aneurysm. Reports on HAR usually analyzed a wide range of aortic arch diseases together, such as aneurysms, traumatic injuries, penetrating atherosclerotic ulcers, and dissections. A recent review on HAR found, irrespective of aortic arch diseases, that 27 studies included 629 patients. ${ }^{12}$ If we focus on studies that included aortic dissection, we found 12 studies accounting for only 92 patients. ${ }^{12}$ In addition, given the clinical heterogeneity of patients treated for aortic dissections reported in these series (acute/chronic stage, therapeutic indication), it is not possible to compare these results or perform crosssectional analysis. ${ }^{12}$

Our series is the first to report the results of HAR specifically for dissecting aneurysm. With a total of 33 patients included, it currently represents the largest series reported in the literature in this area. Its goal is to clarify the value of the hybrid treatment for dissecting aneurysms in terms of morbidity and mortality and to provide technical information on both the supra-aortic trunks transposition and the endovascular procedure to optimize the short- and long-term outcomes of these hybrid procedures.

With a technical success rate of $97 \%$ and the absence of in-hospital mortality, this study shows encouraging early results. In regard to the technical success rate, it is comparable to the rate of $90 \%$ reported by Bünger and colleagues $^{7}$ for HAR for complicated aortic dissections. However, the in-hospital mortality rate reported in this study is higher $(11 \%)$. In this study, treatment in zone 0 appears as a mortality risk factor in multivariate analysis, but the acute or chronic nature of the dissection does not seem to have an impact on it. ${ }^{7}$ We did not perform multivariate analysis because of the number of patients and the low number of events ( 4 deaths), but the proximal anchoring zone does not seem to have any impact on mortality. Indeed, we report a mortality rate of $9 \%$ in patients treated in zone 0 ( 1 death), which is below the mortality rate of patients treated in zone 0 reported in other series of $27 \%,{ }^{13} 30 \%,{ }^{14} 44 \%,{ }^{15}$ and $70 \%$. A recent study reported a mortality rate 3 times higher in patients treated in zone 0 compared with those treated in zone $1 .{ }^{12}$ We reported a rate of retrograde dissection of $3 \%(n=1)$, which is below the rate of $29 \%$ previously reported for hybrid repair of aortic arch dissection. ${ }^{16}$ A recent meta-analysis found that retrograde type A dissection is not associated with the type of stent-graft with or without bare metal stent. ${ }^{5,17}$ Reported risk factors for this complication are oversizing $10 \%$ or more, patient treated for an aortic dissection, and the proximity of the proximal landing zone with the ascending aorta, with an increasing risk in zones 0 and 1 . Therefore, the choice of the appropriate diameter of the stent-graft seems to be essential, rather than the choice of a specific type of stent-graft.

The small number of patients $(\mathrm{n}=11)$ in our series prevents us from drawing conclusions on the reason for this low mortality rate compared with other series. However, we believe that the systematic replacement of the ascending aorta when the diameter is $40 \mathrm{~mm}$ or more, achieving a "rapid pacing" during lateral aortic clamping and during the deployment of the stent-graft, and the choice of a stent-graft with moderate oversizing $(\sim 10 \%)$ are technical elements that help improve short-term and midterm outcomes of these hybrid procedures in zone 0 for dissecting aneurysms, including reducing the risk of retrograde dissection.

The 2 deaths related to aortic pathology that we report are due to the evolution of the dissection upstream (type A dissection) and downstream (dissecting abdominal aortic aneurysm) of the treated area. The extensive and evolving nature of aortic dissection seem to be implicated in the risk of mortality, more than the proximal anchoring zone, which confirms the need to consider the aortic dissection as a progressive disease and thus the need for long-term follow up of these patients. A third death was due to an early 
ischemic esophageal necrosis. This complication is uncommon, with few cases reported in the literature. ${ }^{18,19}$ The exact mechanism of secondary ischemic esophageal necrosis after TEVAR remains unknown; the hypotheses include pressure necrosis caused by the self-expanding endoprosthesis and ischemic esophageal necrosis due to disruption of the arteries that feed the esophagus. ${ }^{18,19}$

In addition, the stroke and medullar complications rates were $6 \%$ and $3 \%$, respectively, which is similar to the rate of stroke of $8.8 \%$ reported by Bünger and colleagues. ${ }^{7}$ Stroke can occur when clamping or be due to embolic problems during the transposition ${ }^{20}$ or during catheterization maneuvers within the aortic arch, ${ }^{11}$ which seem difficult to control. However, we believe that systematic revascularization of the LSA and, in rare cases, the left vertebral artery when arising from the aorta, can reduce this dreaded complication. Furthermore, systematic revascularization of the LSA has been described as reducing the rate of spinal cord complication and cerebrospinal fluid drainage. ${ }^{12,15}$

We report a not inconsiderable rate of local complications $(15 \%)$ in this study. This rate of local complications is higher than in the series by Bünger and colleagues ${ }^{7}$ $(6.6 \%)$ and could be explained by systematic revascularization of the LSA. These complications, such as hematoma or seroma, were not associated with excess mortality; however, they could increase the risk of local infections. Therefore, we prefer to perform direct transpositions rather than prosthetic bypass, even during revascularization in zone 1 , which reduce the risk of infection and improve primary patency. ${ }^{10,21}$

New endovascular techniques to treat lesions in the aortic arch are evaluated, including chimney techniques to stent aortic collateral arteries or the use of branched or fenestrated stent-grafts. These techniques could help address the risk of local complications and represent an alternative therapy in high-risk surgical patients. However, experimentation at the aortic arch remains limited, ${ }^{13,14,22-24}$ and the rate of cerebrovascular complications of endovascular prolonged maneuvers in the aortic arch must be precisely evaluated.

Endoleaks after endovascular repair of the thoracic aorta for aortic dissection are commonly described, with rates of $20 \%,{ }^{6} 27 \%,{ }^{13}$ and $42 \%{ }^{15}$ reported in the literature. With an endoleak rate of $25 \%$, our study confirmed the high incidence of this complication. If all endoleaks do not require reintervention $(3 / 8,37 \%)$, they are a major cause of reintervenion. ${ }^{6}$ It is interesting that the hybrid treatment that allows in theory to obtain a sufficient proximal landing zone in a safe area does not remove the risk of developing proximal endoleaks, which are probably due to the progression of the dissecting disease in these cases.

Although it is not associated with excess mortality, the reintervention rate of these hybrid procedures remains high $(25 \%)$. However, it is not higher than the reintervention rate reported for TEVAR for chronic type $\mathrm{B}$ aortic dissection with associated aneurysm without HAR. ${ }^{25}$ Therefore, a long-term follow-up for these patients is crucial.

\section{CONCLUSIONS}

Hybrid treatment of dissecting aortic arch aneurysm is associated with an acceptable mortality rate, including for patients treated in zone 0 . This treatment provides an important alternative, as a less-invasive approach compared with conventional surgery, especially for high-risk surgical patients. However, given the high rate of endoleaks and reinterventions, long-term follow-up is recommended for these patients.

\section{Conflict of Interest Statement}

Authors have nothing to disclose with regard to commercial support.

\section{References}

1. Tsai TT, Isselbacher EM, Trimarchi S, Bossone E, Pape L, Januzzi JL, et al. Acute type B aortic dissection: does aortic arch involvement affect management and outcomes? Insights from the International Registry of Acute Aortic Dissection (IRAD). Circulation. 2007;116:I150-6.

2. Kim JB, Sundt TM III. Best surgical option for arch extension of type B aortic dissection: the open approach. Ann Cardiothorac Surg. 2014;3:406-12.

3. Kuratani T. Best surgical option for arch extension of type B dissection: the endovascular approach. Ann Cardiothorac Surg. 2014;3:292-9.

4. Schaffer JM, Lingala B, Fischbein MP, Dake MD, Woo YJ, Mitchell RS, et al. Midterm outcomes of open descending thoracic aortic repair in more than 5000 Medicare patients. Ann Thorac Surg. 2015;100:2087-94.

5. Canaud L, Ozdemir BA, Patterson BO, Holt PJ, Loftus IM, Thompson MM. Retrograde aortic dissection after thoracic endovascular aortic repair. Ann Surg. 2014:260:389-95.

6. Faure EM, Canaud L, Agostini C, Shaub R, Böge G, Marty-ané C, et al. Reintervention after thoracic endovascular aortic repair of complicated aortic dissection. J Vasc Surg. 2014;59:327-33.

7. Bünger CM, Kische S, Liebold A, Leißner M, Glass A, Schareck W, et al. Hybrid aortic arch repair for complicated type B aortic dissection. J Vasc Surg. 2013;58: 1490-6.

8. Canaud L, Joyeux F, Ziza V, Branchereau P, Marty-Ané C, Alric P. Hemi-aortic arch debranching for hybrid aortic arch repair by sequential transposition of the left common carotid and subclavian arteries. J Thorac Cardiovasc Surg. 2013; 145:764-7.

9. Eagleton MJ, Greenberg RK. Hybrid procedures for the treatment of aortic arch aneurysms. J Cardiovasc Surg (Torino). 2010;51:807.

10. Canaud L, Hireche K, Berthet JP, Branchereau P, Marty-Ané C, Alric P Endovascular repair of aortic arch lesions in high-risk patients or after previous aortic surgery: midterm results. J Thorac Cardiovasc Surg. 2010;140:52-8.

11. Milewski RK, Szeto WY, Pochettino A, Moser GW, Moeller P, Bavaria JE. Have hybrid procedures replaced open aortic arch reconstruction in high-risk patients? A comparative study of elective open arch debranching with endovascular stent graft placement and conventional elective open total and distal aortic arch reconstruction. J Thorac Cardiovasc Surg. 2010;140:590-7.

12. Cao P, De Rango P, Czerny M, Evangelista A, Fattori R, Nienaber C, et al Systematic review of clinical outcomes in hybrid procedures for aortic arch dissections and other arch diseases. J Thorac Cardiovasc Surg. 2012;144:1286-300.

13. Geisbusch P, Kotelis D, Eschner MM, Hyhlik-Durr A, Bockler D. Complications after aortic arch hybrid repair. J Vasc Surg. 2011;53:935-41.

14. Vallejo N, Rodriguez-Lopez JA, Heidari P, Wheatley G, Caparrelli D, Ramaiah V, et al. Hybrid repair of thoracic aortic lesions for zone 0 and 1 in high risk patients. J Vasc Surg. 2011;55:318-25.

15. Antoniou GA, Mireskandari M, Bicknell CD, Cheshire NJ, Gibbs RG Hamady M, et al. Hybrid repair of the aortic arch in patients with extensive aortic disease. Eur J Vasc Endovasc Surg. 2010;40:715-21. 
16. Cochennec F, Tresson P, Cross J, Desgranges P, Allaire E, Becquemin JP. Hybrid repair of aortic arch dissections. J Vasc Surg. 2013;57:1560-7.

17. Gandet T, Canaud L, Ozdemir BA, Ziza V, Demaria R, Albat B, et al. Factors favoring retrograde aortic dissection after endovascular aortic arch repair. J Thorac Cardiovasc Surg. 2015;150:136-42.

18. De Praetere H, Lerut P, Johan M, Daenens K, Houthoofd S, Fourneau I, et al. Esophageal necrosis after endoprosthesis for ruptured thoracoabdominal aneurysm type I: can long-segment stent grafting of the thoracoabdominal aorta induce transmural necrosis? Ann Vasc Surg. 2010;24:1137.e7-12.

19. Porcu P, Chavanon O, Sessa C, Thony F, Aubert A, Blin D. Esophageal fistula after endovascular treatment in a type B aortic dissection of the descending thoracic aorta. J Vasc Surg. 2005;41:708-11.

20. Gottardi R, Funovics M, Eggers N, Hirner A, Dorfmeister M, Holfeld J, et al. Supra-aortic transposition for combined vascular and endovascular repair of aortic arch pathology. Ann Thorac Surg. 2008;86:1524-9.

21. Cinà CS, Safar HA, Laganà A, Arena G, Clase CM. Subclavian carotid transposition and bypass grafting: consecutive cohort study and systematic review. $J$ Vasc Surg. 2002;35:422-9.
22. Fillinger MF, Greenberg RK, McKinsey JF, Chaikof EL. Reporting standards for thoracic endovascular aortic repair (TEVAR). J Vasc Surg. 2010; 52:1022-33.

23. Chuter TA, Schneider DB, Reilly LM, Lobo EP, Messina LM. Modular branched stent graft for endovascular repair of aortic arch aneurysm and dissection. $J$ Vasc Surg. 2003;38:859-63.

24. Ma H, Yang HY, Zou JJ, Zhang XW. Management with the insufficient proximal landing zone for endovascular repair in aortic dissection. Chin Med J (Engl). 2011;124:3003-7.

25. Parsa CJ, Williams JB, Bhattacharya SD, Wolfe WG, Daneshmand MA, McCann RL, et al. Midterm results with thoracic endovascular aortic repair for chronic type B aortic dissection with associated aneurysm. J Thorac Cardiovasc Surg. 2011;141:322-7.

Key Words: aortic dissection, dissecting aneurysm, aortic arch, hybrid repair

Readers who found these articles interesting may also like to read the following papers found in recent and future issues of our sister publications, Seminars in Thoracic and Cardiovascular Surgery and Operative Techniques in Thoracic and Cardiovascular Surgery!

\section{Acquired: Aortic Disease}

Original Submission: Outcomes of Open Surgical Repair for Type B Dissecting Aortic Aneurysm with Alternative Methods in the Endovascular Stent Era. Mitsumasa Hata. Semin Thorac Cardiovasc Surg 2015; Summer; 27(2):106-112.

Editorial Commentary: It is Difficult to Compare Apples and Oranges: Acute and Chronic Type B Aortic Dissections, Complicated and Uncomplicated, are Different and Should be Treated as Such. Ourania Preventza. Semin Thorac Cardiovasc Surg 2015; Summer; 27(2):113-114.

News and Views: Treatment of Thoracic Aortic Aneurysm: Role of Earlier Intervention. Bulat A. Ziganshin. Semin Thorac Cardiovasc Surg 2015; Summer; 27(2);135-143. 